\title{
Interferência da microbiota autóctone do queijo coalho sobre Staphylococcus coagulase positiva ${ }^{1}$
}

\author{
Interference of autochthonous microbiota of curd cheese on Staphylococcus \\ coagulase positive
}

\author{
Terezinha Feitosa Machado ${ }^{2 *}$, Maria de Fátima Borges ${ }^{2}$, Bruna de Castro Porto ${ }^{3}$, Cívita Teixeira de Sousa ${ }^{3}$ e \\ Francisco Edílson Moreno de Oliveira ${ }^{3}$
}

\begin{abstract}
Resumo - Níveis elevados de contaminantes microbiológicos, comumente encontrados em alimentos de origem animal e ambientes de processamento de alimentos, são aptos de impedir o crescimento de patógenos nestes produtos. Em alguns contextos onde bactérias ácido láticas (BAL) constituem a microbiota dominante, como nos produtos lácteos, Staphylococcus coagulase positiva (SCP) colonizam, persistem e produzem intoxicação alimentar. Com o objetivo de verificar a possível interferência da microbiota encontrada no queijo Coalho sobre a presença de SCP, 64 amostras provenientes de 16 laticínios foram submetidas a análises microbiológicas para determinar os níveis de microrganismos aeróbios mesófilos (MAM), BAL e SCP. Os resultados obtidos mostraram que a microbiota autóctone das amostras analisadas não gerou condições inadequadas ao crescimento, desenvolvimento e isolamento de SCP, uma vez que este patógeno foi detectado mesmo nas amostras que apresentaram altos níveis de contagens de MAM e BAL.
\end{abstract}

Palavras-chave - Segurança alimentar. Staphylococcus aureus. Bactérias produtoras de ácido lático.

\begin{abstract}
High levels of microbial contamination, commonly found in animal origin foods and food processing environments, are able to hinder the growth in these products. In some contexts where lactic acid bacteria (LAB) are the normal dominant microbiota, such as in fermented food, Staphylococcus coagulase positive (SCP) colonises, persists and produces food poisoning. With the aim of verifying the interference of autochthonous microbiota encountered in Curd cheese over the presence of Staphylococcus aureus, 64 samples from 16 dairy were submitted to microbiological analysis to determine the levels of Microorganisms aerobes mesophilics (MAM), LAB and SCP. The results showed that the indigenous microbiota of the samples did not lead to inadequate growth, development and isolation of SCP, since this pathogen was detected even in samples with high levels of counts of AM and BAL.
\end{abstract}

Key words - Food safety. Staphylococcus aureus. Lactic bacterias.

\footnotetext{
* Autor para correspondência

${ }^{1}$ Recebido para publicação em 30/03/2010; aprovado em 24/02/2011

Pesquisa financiada pelo CNPq

${ }^{2}$ Embrapa Agroindústria Tropical, Rua Dra. Sara mesquita, 2270, Pici, Fortaleza-CE, Brasil, 60.511-110, tele@cnpat.embrapa.br, fatima@ cnpat.embrapa.br

${ }^{3}$ Estudante do Curso de Engenharia de Alimentos, Bolsista do projeto, Universidade Federal do Ceará, Av. Mister Hull, 2.977, Alagadico, Caixa Postal

12.168, Fortaleza-CE, Brasil,60.356-000,brunacporto@yahoo.com.br, civitatsou@ig.com.br, edilson_mor_oliver@hotmail.com
} 


\section{Introdução}

A microbiota autóctone de alimentos inclui microrganismos endógenos e contaminantes, decorrentes dos procedimentos higiênicos durante a produção dos mesmos, podendo incluir linhagens capazes de produzir grande variedade de compostos com ação antimicrobiana, que podem impedir a sobrevivência ou inibir o crescimento de patógenos (BAGGE-RAVN et al., 2003).

Os nichos ecológicos naturais de $S$. aureus são as cavidades nasais e a pele de animais de sangue quente. As peculiaridades do seu habitat tornam sua presença largamente distribuída na natureza, sendo transmitido aos alimentos através da matéria prima (p. ex. leite de animal com mastite), do ambiente de processamento ( $p$. ex. biofilmes em superfícies) ou por atividade humana durante o preparo e manipulação (KLUYTMANS; WERTHEIM, 2005). A maioria das cepas é capaz de produzir uma ou mais enterotoxinas (BALABAN; RASOOLY, 2000) responsáveis pelos sintomas gastrointestinais observados durante a intoxicação alimentar (TAMARAPU et al., 2001). Refeições prontas e produtos lácteos fermentados são os alimentos mais envolvidos em intoxicações estafilocócicas (LE LOIR, 2003).

Os efeitos que os compostos antibióticos e os parâmetros físico-químicos $\left(\mathrm{pH}\right.$, temperatura, $\mathrm{H}_{2} \mathrm{O}_{2}$, concentração de sal) exercem sobre a fisiologia de S. aureus têm sido bem estudados (NOVICK, 2003). Entretanto, pouco se sabe sobre a interação entre as células de $S$. aureus e outras pertencentes a diferentes espécies, principalmente dentro de um contexto onde $S$. aureus pode colonizar e persistir em nichos ocupados por outros microrganismos (CHARLIER et al, 2009). Atualmente, há um crescente interesse em interações bacterianas e na compreensão dos mecanismos pelos quais a inibição de patógenos através de outras bactérias pode ocorrer.

As bactérias ácido lático (BAL) constituem um grupo heterogêneo de bactérias cuja principal característica é a habilidade de fermentar açúcares, predominantemente em ácido lático, promovendo uma acidificação ambiental (GALVEZ et al., 2007). Muitas espécies de Lactobacillus têm sido isoladas do trato digestivo; outras, menos onipresentes como L. lactis, evoluíram e se adaptaram a nichos particulares como o leite e derivados (VAN HYLCKAMA VLIEG et al., 2006). Algumas BAL são de interesse na biopreservação de alimentos por sua capacidade de restringir o crescimento de microrganismos indesejáveis, por competição e/ou pela produção de agentes antimicrobianos, entre os quais bacteriocinas (CHEN; HOOVER, 2003), ácidos orgânicos (CHAILLOU et al, 2005) e hipotiocianato (JONES et al, 2008). Alexandre (2002) e Caridi (2003) mostraram a importância do uso desses microrganismos, isolados a partir de leite e queijos, na preservação de alimentos e no controle de patógenos como Staphylococcus spp., Listeria spp., Salmonella spp., Bacillus spp., Pseudomonas spp. e bactérias do grupo coliforme. Posteriormente, Guedes Neto et al (2005) corroboraram esses resultados, relatando que Lactobacillus spp. apresentou respostas antagônicas melhores que Lactococcus spp frente a microrganismos indicadores.

Do ponto de vista de segurança de alimentos e saúde humana, o queijo é um alimento no qual BAL constituem a microbiota predominante e onde $S$. aureus é propenso a desencadear os principais problemas de saúde pública. Contudo, apesar da ocorrência de microrganismos com potencial efeito antagônico sobre a microbiota autóctone do queijo, há relatos na literatura de números elevados de microrganismos patogênicos associados a este produto. Nesse contexto, o objetivo desse trabalho foi avaliar a interferência da microbiota autóctone do queijo Coalho sobre Staphylococcus coagulase positiva (SCP).

\section{Material e métodos}

\section{Amostragem}

Amostras de queijo Coalho provenientes de 16 laticínios foram adquiridas no mercado varejista de Fortaleza e transportadas sob refrigeração para o laboratório de Microbiologia da Embrapa Agroindústria Tropical em caixas isotérmicas contendo gelo. De cada laticínio foram coletados quatro queijos, totalizando 64 amostras. Para as análises, $25 \mathrm{~g}$ de queijo foram homogeneizadas em um Stomacher $^{\circledR}$ (Sewart 400 Circulator), com $225 \mathrm{~mL}$ de solução de citrato de sódio $2 \%$, a $45^{\circ} \mathrm{C}$ e, na sequência, foram preparadas diluições decimais em solução peptona $0,1 \%$, de acordo com Davis e Hickey (2004).

\section{Análises microbiológicas}

Para contagem de SCP, as amostras foram analisadas seguindo o protocolo recomendado por Bennett e Lancette (2001). De cada diluição, foram transferidas alíquotas de $0,1 \mathrm{~mL}$ para a superfície de placas de Petri contendo $25 \mathrm{~mL}$ de Agar Baird Parker, em duplicata. Após a incubação a $35^{\circ} \mathrm{C}$ por $24-48$ horas, foram selecionadas as placas contendo entre 20-200 colônias para contagem. As colônias típicas foram confirmadas por coloração de Gram, prova da coagulase e catalase.

A microbiota autóctone foi determinada pela enumeração de MAM e BAL. De cada amostra, alíquotas de 1,0 $\mathrm{mL}$ das diluições decimais foram adicionadas em Agar para contagem padrão, incubadas a $37^{\circ} \mathrm{C}$ por $48 \mathrm{~h}$ para MAM (LAIRD et al., 2004) e em Agar Man Rogosa 
\& Sharpe (MRS), por plaqueamento em profundidade e sobrecamada do mesmo meio, incubada a $37^{\circ} \mathrm{C}$ por $48 \mathrm{~h}$ para BAL (HALL et al., 2001).

Para análises, as contagens de SCP, MAM e BAL foram convertidas em $\log _{10}$ e expressas em unidades formadoras de colônias por grama $(\log \mathrm{UFC} / \mathrm{g})$. Os dados foram analisados estatisticamente pela análise de variância. Para a comparação múltipla das médias dos tratamentos (produtores) foi utilizado o teste de Tukey ao nível de 5\% de significância (SAS, 1999).

\section{Resultados e discussão}

As contagens médias, por laticínios, para MAM, BAL e SCP estão sumarizadas na Tabela 1. Do total de amostras analisadas, 68,8\% (44/64) apresentaram resposta positiva para $\mathrm{SCP}$, em contagens acima do limite máximo aceitável pela legislação brasileira (3 log UFC/g). As contagens bacterianas variaram de 7,32 a 9,47 log UFC/g para MAM e de 6,38 a 9,36 log UFC/g para BAL. Em relação aos resultados de MAM, observou-se que as médias mais altas de SCP foram detectadas em amostras que apresentaram contagem superior a $8 \log \mathrm{UFC} / \mathrm{g}$ e que contagens até $7 \log \mathrm{UFC} / \mathrm{g}$ de BAL foram eficientes para conter o crescimento de SCP em níveis aceitáveis pelos padrões vigentes. Contudo, a média máxima de 7,86 log UFC/g do patógeno foi alcançada quando a média de BAL foi de $8,38 \log \mathrm{UFC} / \mathrm{g}$.

Os valores encontrados neste estudo assemelham-se aos encontrados por Queiroga et al. (2009). Estes autores, em estudo com queijo Minas frescal, relataram contagens médias de MAM variando entre 6,69 e 9,49 log UFC/g e de Staphylococcus spp. entre 5,1 e 7,70 log UFC/g. Observaram, ainda, que as mais altas médias de contagem de Staphylococcus spp. foram obtidas em amostra com MAM acima de 7,0 log UFC/g.

Um dos principais objetivos da indústria de alimentos é fornecer alimentos seguros, saudáveis e aceitáveis para o consumidor. Para que esse objetivo seja atingido é essencial o controle de microrganismos, que é parcialmente exercido pelo processamento e pelas técnicas de preservação, bem como pelo efeito antagônico que algumas linhagens bacterianas da flora autóctone têm sobre estes microrganismos (BAGGERAVN et al., 2003). Alexandre et al. (2002), constataram que $25 \%$ de cepas de BAL isoladas de queijo Minas Frescal (48/192) foram capazes de inibir o crescimento in vitro de microrganismos indicadores, dentre os quais Staphylococcus aureus. Neste estudo a inibição do

Tabela 1 - Contagem de bactérias MAM, BAL e SCP $(\log$ UFC/g) em amostras de queijo Coalho provenientes de 16 laticínios. Comparação múltipla das médias pelo teste de Tukey ao nível de 5\% de significância. Letras diferentes sobrescritas na mesma linha indicam diferença significante

\begin{tabular}{cccc}
\hline Laticínio & MAM & BAL & SCP \\
\hline 1 & $9,90 \pm 0,58 \mathrm{a}$ & $9,34 \pm 0,61 \mathrm{ab}$ & $5,41 \pm 3,61 \mathrm{~b}$ \\
2 & $9,47 \pm 0,54 \mathrm{a}$ & $9,36 \pm 0,20 \mathrm{a}$ & $6,35 \pm 3,25 \mathrm{a}$ \\
3 & $9,42 \pm 1,08 \mathrm{a}$ & $8,53 \pm 0,34 \mathrm{a}$ & $6,25 \pm 3,45 \mathrm{a}$ \\
4 & $9,33 \pm 0,27 \mathrm{a}$ & $9,20 \pm 0,16 \mathrm{a}$ & $5,57 \pm 4,19 \mathrm{~b}$ \\
5 & $9,21 \pm 0,56 \mathrm{a}$ & $9,38 \mathrm{a}$ \\
6 & $9,04 \pm 0,19 \mathrm{a}$ & $8,0 \pm 0,0 \mathrm{~b}$ \\
7 & $8,90 \pm 0,33 \mathrm{a}$ & $5,07 \pm 4,0 \mathrm{a}$ \\
8 & $8,85 \pm 0,46 \mathrm{a}$ & $7,90 \pm 0,22 \mathrm{a}$ & $7,86 \pm 2,68 \mathrm{a}$ \\
9 & $8,73 \pm 0,24 \mathrm{a}$ & $6,60 \pm 3,15 \mathrm{a}$ \\
10 & $8,63 \pm 0,26 \mathrm{a}$ & $4,91 \pm 4,07 \mathrm{a}$ \\
11 & $8,04 \pm 0,93 \mathrm{a}$ & $8,90 \pm 0,60 \mathrm{a}$ & $0,0 \pm 0,0 \mathrm{~b}$ \\
13 & $8,04 \pm 0,16 \mathrm{a}$ & $8,72 \pm 0,15 \mathrm{a}$ & $7,0 \pm 2,42 \mathrm{a}$ \\
14 & $7,98 \pm 0,72 \mathrm{a}$ & $7,21 \pm 0,58 \mathrm{a}$ & $0,0 \pm 0,0 \mathrm{~b}$ \\
15 & $7,87 \pm 0,86 \mathrm{a}$ & $7,89 \pm 1,41 \mathrm{a}$ & $6,81 \pm 2,94 \mathrm{a}$ \\
16 & $7,32 \pm 1,45 \mathrm{a}$ & $7,45 \pm 1,58 \mathrm{a}$ & $0,54 \pm 1,94 \mathrm{~b}$
\end{tabular}

MAM: microrganismos aeróbios mesófilos; BAL: bactérias ácido láticas; SCP: Staphylococcus coagulase positiva 
crescimento de S. aureus foi evidenciada apenas em amostras provenientes de três laticínios, correspondendo a 19\% das amostras analisadas (12/64), resultados estes inferiores aos citados por aqueles autores.

S. aureus é um importantes patógeno humano, que produz uma grande variedade de toxinas, causando diversos tipos de doenças. Considerando os seus nichos ecológicos naturais, cavidades nasais e pele de animais de sangue quente, associados à sua capacidade de crescer em amplo intervalo de temperatura $\left(7^{\circ} \mathrm{C}\right.$ a $48,5^{\circ} \mathrm{C}$, com temperatura ótima entre 30 a $\left.37^{\circ} \mathrm{C}\right), \mathrm{pH}(4,2$ a 9,3 com ótimo de 7 a 7,5 ) e cloreto de sódio (até $15 \%$ de), a presença dessa bactéria no alimento, em parte, é decorrente da ausência de medidas preventivas devidamente aplicadas (BALABAN; RASOOLY, 2000; KLUYTMANS; WERTHEIM, 2005). Os resultados das contagens de SCP, BAL e MAM obtidas neste estudo são considerados elevados, o que sugere uma possível negligência na linha de produção do queijo Coalho, que envolve desde a saúde do animal, passando pela matéria prima, processamento, manipulação, distribuição e armazenamento do produto.

Em determinadosalimentos ondeas BAL constituem a microbiota dominante, $S$. aureus pode colonizar, persistir e produzir enterotoxinas, desencadeando assim processos de intoxicação alimentar (LE LOIR, 2003). Estudos desenvolvidos sobre a interação entre BAL e $S$. aureus constataram que a possível interferência das primeiras sobre esta última bactéria varia em função de diversos fatores como acidificação, produção de bacteriocina, produção de peróxido de hidrogênio $\left(\mathrm{H}_{2} \mathrm{O}_{2}\right)$ e competição nutricional (NOVICK, 2003; CHARLIER, 2009). Contudo, o efeito deletério de cada um desses fatores varia em função de outros. Por exemplo, cepas de $S$. aureus são mais sensíveis à acidificação quando a concentração de sal é alta (resultando em uma menor atividade de água), embora $S$. aureus seja halo tolerante (IANDOLO et al., 1964). Similarmente, Kaban e Kaya (2006) demonstraram que a utilização de uma cultura starter com diferentes espécies de Lactobacillus na produção de salsicha fermentada aumentou a média de acidificação do produto e, como consequência, promoveu uma redução no nível de contaminação por $S$. aureus. Ito et al. (2003) observaram que cepa de L. lactis, produtoras de grande quantidade de $\mathrm{H}_{2} \mathrm{O}_{2}$ apresentaram pouco efeito sobre $S$. aureus. Contudo, Otero et al. (2006) relataram forte ação antagônica de $\mathrm{H}_{2} \mathrm{O}_{2}$ produzido por Lactobacillus spp. sobre $S$. aureus provenientes de gado leiteiro com mastite. Entretanto, Charlier et al (2009), avaliando a interação entre $S$. aureus e BAL, relataram que ainda é controverso o papel do $\mathrm{H}_{2} \mathrm{O}_{2}$ produzido por BAL sobre este patógeno. Outro fator a ser considerado na interação entre Staphylococcus spp. e BAL é a produção de bacteriocinas por estas últimas, as quais podem apresentar efeito bacteriostático
(COTTER et al., 2005) ou bactericida sobre algumas espécies (GALVEZ et al., 2007). Por outro lado, embora sejam poucas as pesquisas que relatam a capacidade de $S$. aureus produzir bacteriocinas, a produção destas pelo patógeno foi descrita por Jetten e Vogels em 1973. Esta habilidade pode conferir ao patógeno vantagem sobre outros microrganismos que competem pelo mesmo nicho ecológico no qual BAL são prevalentes.

Considerando que as possíveis interferências da microbiota autóctone de um alimento sobre $S$. aureus são variáveis em função de diversos fatores, os resultados obtidos neste estudo sugerem que a microbiota autóctone, nas amostras de queijo Coalho analisadas, não afetou de forma significativa a sobrevivência ou o crescimento de SCP no mesmo.

\section{Conclusão}

A microbiota autóctone do queijo Coalho, independente do laticínio onde foi produzido, não gerou condições desfavoráveis ao crescimento, desenvolvimento e isolamento de SCP.

\section{Agradecimento}

Os autores agradecem ao $\mathrm{CNPq}$ pelo suporte financeiro dado a essa pesquisa.

\section{Referências}

ALEXANDRE, D. P. et al. Atividade antimicrobiana de bactérias lácticas isoladas de queijo-de-minas artesanal do Serro (MG) frente a microrganismos indicadores. Arquivo Brasileiro de Medicina Veterinária e Zootecnia, v. 54, n. n. 04, p. 424-428, 2002.

BAGGE-RAVN, D. et al. The microbial ecology of processing equipment in different fish industries- analysis of the microflora during processing and following cleaning and disinfection. International Journal of Food Microbiology, v. 87, n.03 p. $239-250,2003$.

BALABAN, N., RASOOLY, A. Staphylococcal enterotoxins. International Journal of Food Microbiology, v. 61 n. 01, p.1-10, 2000.

BENNETT, R. W.; LANCETTE, G. A. Stapylococcus aureus. In: FOOD AND DRUG ADMINISTRATION. Bacteriological Analitical Manual on line. 2001. Disponível em: $<\mathrm{http}: / / \mathrm{www}$. cfsan.fda.gov/-bam 5 html>. Acesso em: 19 abr. 2006.

CARIDI, A. Ripening and seasonal changes in microbial groups and in physicochemical properties of the ewes' 
cheese Pecorino del Poro. International Dairy Journal, v. 13, n.02/03, p. 191-200, 2003.

CHAILLOU, S. et al. The complete genome sequence of the meat-borne lactic acid bacterium Lactobacillus sakei $23 \mathrm{~K}$. Nature Biotechnology, v. 23, p. 1527-1533, 2005.

CHARLIER, C. et al. Interactions between Staphylococcus aureus and lactic acid bacteria: an old story with new perspectives. International Journal of Food Microbiology, v. 131, p. $30-39,2009$.

CHEN, H.; HOOVER, D. G. Bacteriocins and their food applications. Food Science Food Safety, v. 02, n. 30, p. 82100, 2003.

COTTER, P. D.; HILL, C.; ROSS, R. P. Bacteriocins: developing innate immunity for food._Nature Reviews Microbiology, v. 03, n. 10, p. 777-788, 2005.

DAVIS, G. L.; HICKEY, P. J. Media and dilution water preparation. In: WEHR, H. M.; FRANK, J. F. Standard Methods for the Examination of Dairy Products. $17^{\text {th }}$ ed. American Public Health Association, Washington, D. C., 2004. cap. 4 , p. 93-101.

GALVEZ, A. et al. Bacteriocin-based strategies for food biopreservation. International Journal of Food Microbiology, v. 120 , n. $01 / 02$, p. $51-70,2007$.

GUEDES NETO, L. G. et al. Atividade antimicrobiana de bactérias ácido-lácticas isoladas de queijos de coalho artesanal e industrial frente a microrganismos indicadores. Arquivo Brasileiro de Medicina Veterinária e Zootecnia, v.57, p.245-250, 2005. Suplemento 2.

HALL, P. A.; LEDENBACH, L.; FLOWERS, R. S. Acidproducing microorganisms. In: DOWNES, F. P.; ITO, K. Compendium of Methods for the Microbiological Examination of Foods. $4^{\text {th }}$ ed. Washington: American Public Health Association, , 2001. cap.19, p. 201-207.

IANDOLO, J. J.; ORDAL, Z. J.; WITTER, L. D. The effect of incubation temperature and controlled $\mathrm{pH}$ on the growth of Staphylococcus aureus Mf 31 at various concentrations of $\mathrm{NaCl}$. Canadian Journal of Microbiology, v. 10, p. 808-811, 1964.

ITO, A. et al. The screening of hydrogen peroxide-producing lactic acid bacteria and their application to inactivating psychrotrophic food-borne pathogens. Current Microbiology, v. 47, n. 03 , p. $231-236,2003$.
JETTEN, A. M.; VOGELS, G. D. Characterization and extrachromosomal control of bacteriocin production in Staphylococcus aureus. Antimicrobial Agents and Chemotherapy, v. 04, n.01 p. 49-57, 1973.

JONES, R. J. et al. Isolation of lactic acid bacteria with inhibitory activity against pathogens and spoilage organisms associated with fresh meat. Food Microbiology, v. 25, n.02 p. 228-234, 2008.

KABAN, G.; KAYA, M. Effect of starter culture on growth of Staphylococcus aureus in sucuk. Food Control, v. 17n.10 p. 797-801, 2006.

KLUYTMANS, J. A. J. W.; WERTHEIM, H. F. L. Nasal carriage of Staphylococcus aureus and prevention of nosocomial infections. Infection, v. 33, n. 01 p. 3-8, 2005.

LAIRD, D. T. et al. Microbiological count methods. In: WEHR, H. M.; FRANK, J. F. Standard Methods for the Examination of Dairy Products. $17^{\text {th }}$ ed. Washington: American Public Health Association, 2004. cap.6, p. 153-186.

LE LOIR, Y.; BARON, F.;GAUTIER, M. Staphylococcus aureus and food poisoning. Genetics and Molecular Research, v. 02, n. 01, p. $63-76,2003$.

NOVICK, R. P. Autoinduction and signal transduction in the regulation of staphylococcal virulence. Molecular Microbiology, v. 48, n. 06, p. 1429-1449, 2003.

OTERO, M. C.; MORELLI, L.; NADER-MACIAS, M. E. Probiotic properties of vaginal lactic acid bacteria to prevent metritis in cattle. Letters in Applied Microbiology, v. 43, n. 01, p. 91-97, 2006.

QUEIROGA, R. C. R. E. et al. Elaboração e caracterização físico-química, microbiológica e sensorialde queijo "tipo minas frescal" de leite de cabra condimentado. Revista Ciência Agronômica, Fortaleza, v. 40, n. 03, p. 363-372, 2009.

SAS. Sas Institute Inc., Cary, NC, 1999.

TAMARAPU, S.; MCKILLIP, J. L.; DRAKE, M. Development of a multiplex Polymerase chain reaction assay for detection and differentation of Staphylococcus aureus in dairy products. Journal Food Protection, v. 64, n. 05, p. 664-668, 2001.

VAN HYLCKAMA VLIEG, J. E. et al. Natural diversity and adaptive responses of Lactococcus lactis. Current Biotechnology. v. 17, p. 183-190, 2006. 